\title{
Improving Communication of Critical Test Results in a Pediatric Academic Setting: Key Lessons in Achieving and Sustaining Positive Outcomes
}

Cheryl Jackson, Maureen MacDonald, Michael Anderson, Polly Stevens, Philip Gordon and Ronald Laxer

\begin{abstract}
By applying the Institute for Healthcare Improvement's framework for strategic change (will, ideas and execution), The Hospital for Sick Children, in Toronto, Ontario, developed processes to improve patient safety through the effective communication of critical test results. In response to an adverse patient event, near misses and accreditation requirements, a task force with representatives from the laboratories and clinical services was established to ensure the timely and reliable communication of critical test results for biochemistry, hematology, coagulation, therapeutic drug monitoring and microbiology. The task force critically assessed processes and best practices, identified practical alternatives, tested changes, codified new processes in a hospital-wide policy and procedure and carried out post-implementation outcome audits. Lessons learned in sustaining improvements included the following: there is value in identifying strategies from a larger system perspective; there exist merits to working collaboratively as an inter-professional team (i.e., laboratory and clinical leaders); there is value in learning from failure; higher-cost but "higher-leverage" approaches can be pivotal; and regular monitoring and vigilance of policy compliance are required.
\end{abstract}

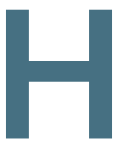

ealthcare regulatory bodies and professional groups acknowledge that the failure to report critical test results (CTR) in a timely and reliable way is a threat to patient safety and healthcare quality. In 2007, Accreditation Canada (formerly the Canadian Council on Health Services Accreditation [CCHSA]) incorporated as a required organizational practice expectations regarding the verification processes for high-risk activities such as the "communication of critical test results" (CCHSA 2007). The Joint Commission in the United States emphasized in their 2005 National Patient Safety Goals the requirements to "measure, assess and if appropriate, take action to improve the timeliness of reporting and timeliness of receipt by the responsible licensed caregiver, of critical test results and values." (Joint Commission 2006). Two years later in 2007, the Joint Commission reported that $36 \%$ of hospitals surveyed did not meet this important patient safety goal (Joint Commission 2008).

In one study, $95 \%$ of physicians considered calls about critical results to be helpful in care management, with $75 \%$ noting critical results in the medical record and $66 \%$ indicating that critical results have prompted some change in therapy (Howanitz et al. 2002). From a risk management perspective, Zettle highlighted that "[hospitals had a] direct obligation to see to it that suitable procedures were in place to verify that vital test results were received and made available to the treating physi- 
cian. It was simply not enough for the hospital to rely on the physician as the ultimate caregiver to shoulder the entire responsibility" (Zettle 2006: 6). Finally, from a laboratory perspective, critical value reporting parameters are recognized as an important outcome measurement, reflecting clinical effectiveness, patient safety and operational efficiency (Dighe et al. 2006).

\section{Setting the Stage for Change: Will}

At The Hospital for Sick Children (SickKids), a 275-bed tertiary and quaternary pediatric academic health sciences centre in Toronto, Ontario, interdisciplinary teams of staff and trainees provide complex, critical and chronic care to patients and families in the in-patient, emergency department and ambulatory settings. The reporting of safety events and investigations of critical incidents are important components of our patient safety strategy (Stevens et al. 2005). A critical incident involving a misdirected and delayed communication of a significant laboratory test result for a dialysis patient and a review of all safety reports associated with CTR revealed gaps in our processes. These events drove the leadership will to improve communication of CTR and led to the formation of a Communication of Critical Test Results Task Force. The task force was charged with reviewing existing processes at SickKids and recommending changes to improve the safe and timely communication of CTR. The task force adopted a framework developed by the Institute for Healthcare Improvement (IHI) (Nolan 2007) that outlines the essential elements for strategic improvement: will, ideas and execution. The will to improve communication of CTR was driven by the fact that our safety reports demonstrated significant challenges with this communication, as well as emerging accreditation requirements.

The task force was composed of a large interdisciplinary group representing the complexities of the organizational structure and patient populations. The scope of the task force's work was the communication of CTR affiliated with the rapid response laboratory (clinical biochemistry, hematology, coagulation and therapeutic drug monitoring) and the microbiology laboratory.

The task force adopted the following operational definitions:

- Critical test values: test values that are so abnormal that they can indicate a potentially life-threatening situation in a patient or a disease state that requires immediate medical attention

- Responsible provider: responsible physician or delegate (e.g., trainee as fellow or resident) who has responsibility to assess, intervene and manage a patient's healthcare and who has the authority to respond and act upon the critical test promptly and effectively to ensure quality patient care

- Escalation steps: steps undertaken by laboratory staff if unsuccessful in contacting the designated "first contact" within an acceptable time period (i.e., if first call or page is unanswered in 10 minutes, laboratory staff will repeat the call or page; if still unanswered after 20 minutes, staff will page alternate contact)

\section{"Hospitals had a direct obligation to see to it that suitable procedures were in place to verify that vital test results were received and made available to the treating physician."}

\section{Determining the Focus for Change Initiatives: Ideas}

The task force called upon three principal sources for ideas to determine alternatives to the status quo: (1) a modified failure modes and effects analysis (FMEA) process to identify high-risk steps in communicating CTR and priorities for change; (2) a literature review of best practices in academic health organizations; and (3) guiding principles, tools and strategies from the Massachusetts Coalition for the Prevention of Medical Errors (Schiff et al. 2006).

The FMEA process uncovered three steps as high risk and priorities for improvement at SickKids including the submission of a complete laboratory requisition, the discovery of CTR and calling the responsible provider with CTR. The review of best practices and the coalition recommendations emphasized the importance of addressing the following key questions: Who should receive CTR? Who should receive CTR when the ordering provider is not available? What CTR require timely and reliable communication?

Table 1 outlines key practice recommendations for communication of CTR (Hanna et al. 2005), identified vulnerabilities at SickKids and identified changes.

\section{Implementing Change Initiatives: Execution \\ Changes were focused in the following areas:}

1. Defining lists of critical values to be communicated

2. Identifying who to call

3. Establishing explicit time frames for calls

\section{Defining Lists of Critical Values to Be Communicated}

Consultation and consensus building directed the process of reviewing and updating critical test values for the rapid response and microbiology laboratories. The critical values were organized into five lists: clinical biochemistry, hematology, coagulation, therapeutic drug monitoring and microbiology. Leadership from both the executive and clinicians was pivotal to this process and to obtaining feedback on the needs of 
Table 1. Communicating CTR: safe practices, vulnerabilities at SickKids and proposed changes

\begin{tabular}{|c|c|c|}
\hline $\begin{array}{l}\text { Safe Practice } \\
\text { Recommendations* }\end{array}$ & $\begin{array}{l}\text { Identified Vulnerabilities in SickKids } \\
\text { Processes }\end{array}$ & Ideas and Changes \\
\hline $\begin{array}{l}\text { Identify who should receive } \\
\text { the results }\end{array}$ & $\begin{array}{l}\text { Hospital mandate for teaching medical trainees and } \\
\text { advance practitioners set stage for complexity in } \\
\text { determining who to call } \\
\text { Complex patients managed by multiple services } \\
\text { and physicians ordering tests on same laboratory } \\
\text { requisition } \\
\text { Laboratory order requisitions for chronic patients } \\
\text { generated in advance and offering inaccurate } \\
\text { ordering physician }\end{array}$ & $\begin{array}{l}\text { Determine short- and long-term goals for who should } \\
\text { receive results (ideal to contact the ordering provider for } \\
\text { all CTR) } \\
\text { Maintain nursing staff as intermediary to receive in-patient } \\
\text { and ED CTR due to infrastructure limitations } \\
\text { Review ED protocol in place for handling discharged } \\
\text { patients' CTR }\end{array}$ \\
\hline $\begin{array}{l}\text { Identify who should receive } \\
\text { the results when the } \\
\text { ordering provider is not } \\
\text { available }\end{array}$ & $\begin{array}{l}\text { Specific areas supported the communication of CTR } \\
\text { to clerical staff } \\
\text { Nurses and other regulated health professionals } \\
\text { accepting CTR not aware of what to do with results } \\
\text { (i.e., actions and time frame to relay) and/or not } \\
\text { supported by written protocols } \\
\text { Unclear ownership for accepting ambulatory patients' } \\
\text { CTR "off hours" }\end{array}$ & $\begin{array}{l}\text { Enforce and monitor compliance with policy rule not to } \\
\text { communicate CTR to a non-regulated health professional or } \\
\text { team member (e.g., clerk) } \\
\text { Articulate clear escalation steps and time frames if first } \\
\text { contact not available }\end{array}$ \\
\hline $\begin{array}{l}\text { Define which test results } \\
\text { require timely and reliable } \\
\text { communication }\end{array}$ & $\begin{array}{l}\text { Lists for different laboratories' critical values found in } \\
\text { laboratory-based documents } \\
\text { No formal process involving laboratory and clinical } \\
\text { leadership to review and revise lists for critical values } \\
\text { to be called }\end{array}$ & $\begin{array}{l}\text { Consult extensively with clinical services and laboratory } \\
\text { leadership to approve parameters for communicating CTR } \\
\text { Consolidate lists of all laboratories' critical values within } \\
\text { one hospital-wide policy } \\
\text { Educate clinical teams and laboratory staff on CTR call } \\
\text { parameters } \\
\text { Customize LIS to identify individual results requiring a call } \\
\text { based on the defined list }\end{array}$ \\
\hline $\begin{array}{l}\text { Identify when test result } \\
\text { should be actively reported } \\
\text { to the ordering provider } \\
\text { and establish explicit time } \\
\text { frames for this process }\end{array}$ & $\begin{array}{l}\text { Laboratory-based policies directed laboratory staff } \\
\text { that "critical values are telephoned immediately upon } \\
\text { verification of accuracy"; no explicit time frames were } \\
\text { set if unable to reach care provider }\end{array}$ & $\begin{array}{l}\text { Articulate explicit steps and time frames for repeating and } \\
\text { escalating calls if first call/page unsuccessful } \\
\text { Address unique challenges posed by ambulatory-based } \\
\text { results and off-hours CTR }\end{array}$ \\
\hline $\begin{array}{l}\text { Identify how to notify the } \\
\text { responsible provider(s) }\end{array}$ & $\begin{array}{l}\text { Adverse events identified in safety reports due to use } \\
\text { of voicemail to communicate CTR } \\
\text { Specific physicians requested laboratory call by } \\
\text { phone rather than pager }\end{array}$ & $\begin{array}{l}\text { Establish rules and monitor infractions for calls left on } \\
\text { voicemail and/or communicated to non-regulated health } \\
\text { provider }\end{array}$ \\
\hline $\begin{array}{l}\text { Establish a shared policy for } \\
\text { uniform communication of } \\
\text { all types of test results to all } \\
\text { recipients }\end{array}$ & $\begin{array}{l}\text { Rapid response laboratory, TDM and microbiology } \\
\text { laboratory had individual policies directing staff on } \\
\text { CTR processes }\end{array}$ & $\begin{array}{l}\text { Create single hospital-wide policy available electronically } \\
\text { on policy and procedure database } \\
\text { Standardize processes across laboratories } \\
\text { Roll out new policy }\end{array}$ \\
\hline $\begin{array}{l}\text { Design reliability into the } \\
\text { system }\end{array}$ & $\begin{array}{l}\text { No data available to track timeliness and } \\
\text { appropriateness of communicating CTR }\end{array}$ & $\begin{array}{l}\text { Install LIS callback module to provide data (reports) for } \\
\text { daily review and monitoring of CTR calls } \\
\text { Implement read back as a required function with LIS } \\
\text { upgrade } \\
\text { Establish laboratory call centre (Mon-Fri day shift) }\end{array}$ \\
\hline $\begin{array}{l}\text { Support and maintain } \\
\text { systems }\end{array}$ & $\begin{array}{l}\text { Pitfalls/gaps identified within different patient } \\
\text { information systems }\end{array}$ & $\begin{array}{l}\text { Identify requirements for upgrades and functionality of new } \\
\text { systems }\end{array}$ \\
\hline $\begin{array}{l}\text { Support infrastructure } \\
\text { development }\end{array}$ & $\begin{array}{l}\text { Lack of transfer of patient and service information } \\
\text { between hospital information systems }\end{array}$ & $\begin{array}{l}\text { Investigate laboratory use of online on-call schedules; } \\
\text { adapt for use by laboratories }\end{array}$ \\
\hline
\end{tabular}

$C T R=$ critical test results; $E D=$ emergency department; LIS = laboratory information system; SickKids = Hospital for Sick Children; TDM = therapeutic drug monitoring .

${ }^{*}$ As per Hanna et al. (2005). 
specific services (e.g., critical care), while ensuring a hospitalwide perspective was maintained. As the laboratory information system (LIS) has the flexibility to allow for rule creation, complex exclusion criteria and a short list of hematological and biochemical critical test values were accepted for specific patient populations (i.e., patients in hematology/oncology, critical care or the neonatal intensive care unit) to prevent the over-calling of results. Additionally, specific exceptions were granted not to call cardiology for critical values of partial thromboplastin time for in-patients or endocrinology for critical values of glucose for those in the diabetes clinic, given the following conditions: (1) abnormal results are expected due to the patients' underlying disease process or treatment regimen and (2) these services monitor their patients' CTR electronically.

\section{Identifying Who to Call}

With an overall goal of getting the CTR to a responsible physician or delegate who has the responsibility to assess, intervene and manage the patient's healthcare and who has the authority to respond and act upon the CTR promptly and effectively to ensure quality patient care, a key step for the task force was to determine the appropriate care provider to receive the communication of CTR and to establish standardized processes for calling (i.e., rules for first and backup contacts and explicit escalation steps if unsuccessful in reaching the appropriate care provider).

To reach a consensus on this issue, the task force executive sponsor surveyed all division chiefs seeking feedback on first call and backup call for all in-patient, emergency department (ED) and ambulatory-based CTR. Consultations were also held with nursing leaders.

Following lengthy discussions, debates and feedback, the majority of staff physicians agreed with the ideal goal of the ordering physician or delegate (defined as the medical trainee or regulated healthcare professional) being the first contact for all CTR. It was subsequently determined that the hospital's information systems could not support this goal, particularly if the patient's primary service at the time of ordering was not the same as that at time of specimen accessioning and reporting (e.g., an ED patient is transferred to the critical care unit). It was conceded that the reporting of in-patient and ED CTR ( $80 \%$ of total CTR) would be to nursing staff, whereas, for ambulatory clinics and daycare units, reporting would be to the ordering physician or delegate. Most importantly, two rules were established and infractions monitored: (1) CTR would not be left on voicemail and (2) CTR would not be communicated to a non-regulated healthcare professional (e.g., a unit clerk).

\section{Establishing Explicit Time Frames for Calls}

Acceptable time frames were determined through a review of industry best practices and by evaluating what was realistic for SickKids. The time frame for communicating CTR to in-patient units and the ED was established as less than 30 minutes, whereas for ambulatory areas, the time frame is less than 60 minutes.

\section{Ongoing Challenges}

A policy was developed that outlined all of the above and was communicated to the staff throughout the institution. Post-implementation, ongoing challenges were seen, particularly with ambulatory-based CTR. The Model of Improvement (Langley et al. 2006) was used as a framework to identify, test and evaluate additional improvement ideas in this area. Concurrent Plan-Do-Study-Act cycles were used; these are depicted in Figure 1.

These cycles highlighted the value of testing ideas and using staff feedback to determine if the changes fit the unique environments in different daycare units and clinics. These cycles led to customized approaches for calling the daycare units. Significant patient characteristics (e.g., chronic health conditions and treatment regimens) and care provider characteristics (e.g., timing of preparing laboratory requisitions, changes in clinical coverage due to other role responsibilities such as teaching and research) highlighted the need for the laboratory to take an extra step in confirming who the responsible provider was at the time of CTR reporting. Another challenge related to the role of trainees as a backup for ambulatory-based CTR as this represented a change in their usual role.

Follow-up with staff physicians who had demonstrated a pattern of not responding to pages in a timely fashion revealed issues related to not carrying pagers for coverage of ambulatory patients; an incorrect staff physician being listed as the ordering physician; and pagers being delegated to an inappropriate team member (e.g., clinic clerk) when physician was busy with patient care or other role responsibilities.

\section{Two rules were established: CTR would not be left on voicemail and would not be communicated to a non-regulated healthcare professional.}

\section{Tracking Effectiveness of Change Strategies: Evaluation}

In order to evaluate the effectiveness of change strategies, it was paramount that we establish the ability to track data on the timeliness and appropriateness of CTR call processes. Prior to implementing the new policy, baseline data were not available. Later in the process, an LIS callback module and call centre were implemented, providing the ability to track each communication of CTR from the time of the results to the time of communication to the appropriate care provider. Currently, a 
Figure 1. Improvement initiatives for ambulatory-based critical test results

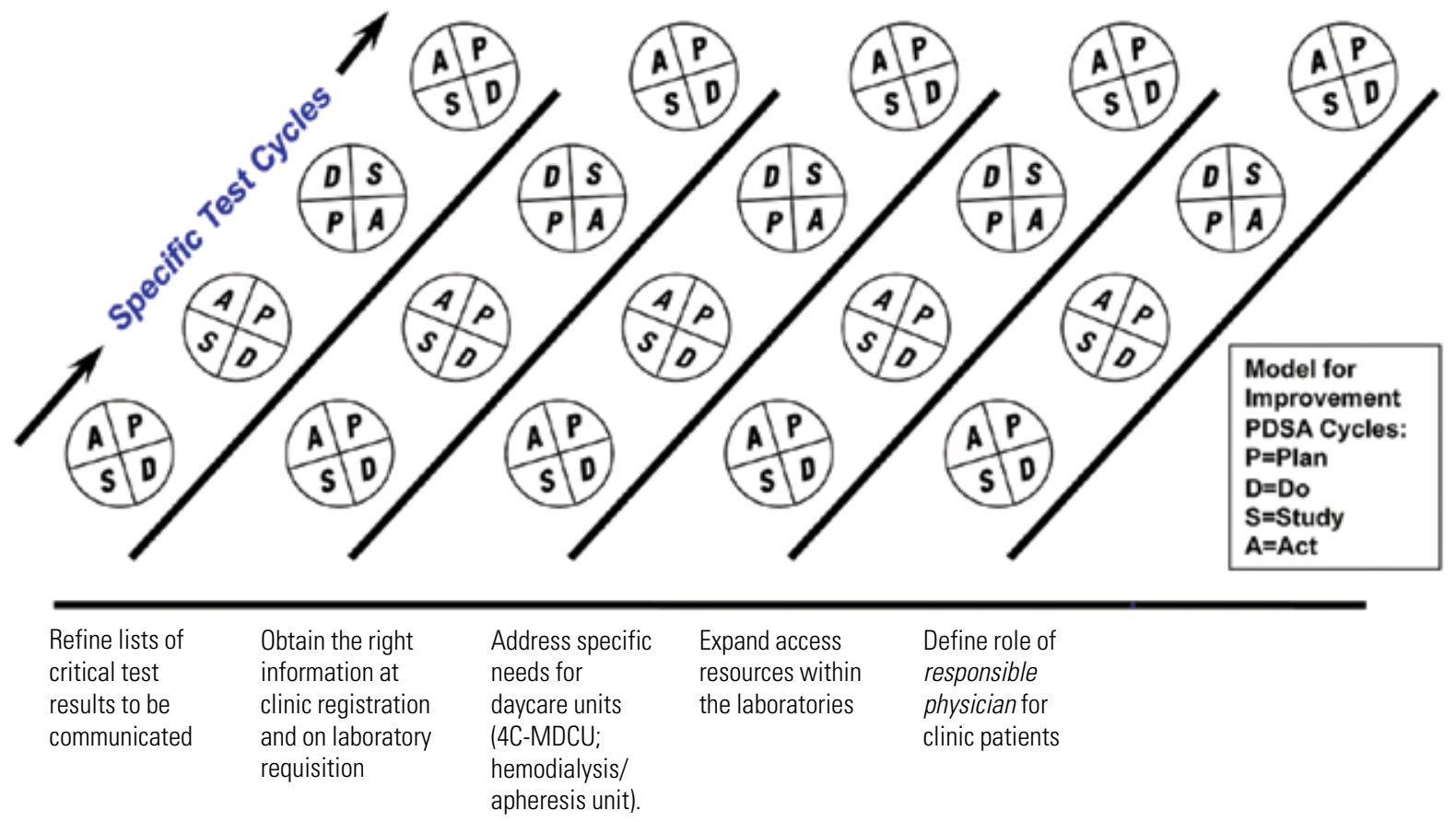

Table 2. Top barriers in achieving targets

\begin{tabular}{|l|l|l|}
\hline Information Systems & Laboratory & Clinical Teams \\
\hline Inability to identify patient location 24/7 & Not escalating calls within set time frames & Inaccurate or incomplete information on submitted \\
Inability to identify patient's primary service & First call delayed due to other work role & laboratory requisition \\
in LIS & commitments & Not responding to pages if busy with patient care or \\
Complexity of online on-call schedule is & Poor availability of call centre staff and & teaching rounds \\
difficult for laboratory staff to navigate & service hours & Trainee not familiar with patient or call processes \\
Health professional unable to acknowledge & Attempting to find ordering physician via & (i.e., backup role) \\
CTR reviewed electronically and avoid need & informal channels & Calls not picked up by in-patient unit, or laboratory \\
for laboratory to call & Forgetting to check outstanding CTR calls & staff left on hold \\
Paper and electronic laboratory requisitions & in callback module & Routine laboratory requisitions sent in early morning, \\
submitted & & which effects workflow due to limited resources \\
\hline
\end{tabular}

CTR = critical test results; LIS = laboratory information system

daily callback status report is generated with the statuses of the previous day's CTR calls. Laboratory leadership review these reports to ensure all calls were performed efficiently and appropriately. Any calls requiring excess time and outliers involving "missed calls" or "calls to an inappropriate provider" are followed up and analyzed to determine if there was an impact on patient outcome. For example, three calls identified as communicated to inappropriate provider were associated with physicians' delegation to a clerk in an ambulatory care setting, and physician knowledge of CTR was affirmed. It has now been more than 12 months since the occurrence of a significant CTR missed call. Challenging calls are reviewed with laboratory staff and clinical teams to determine system-related factors. Physicians have provided feedback regarding difficulty in accessing a laboratory phone as a factor impacting their timely response to pages. As a result, a dedicated line was established for CTR calls. The top factors identified as barriers to achieving efficient calls are outlined in Table 2 . 
Figure 2. Data regarding compliance of CTR communication

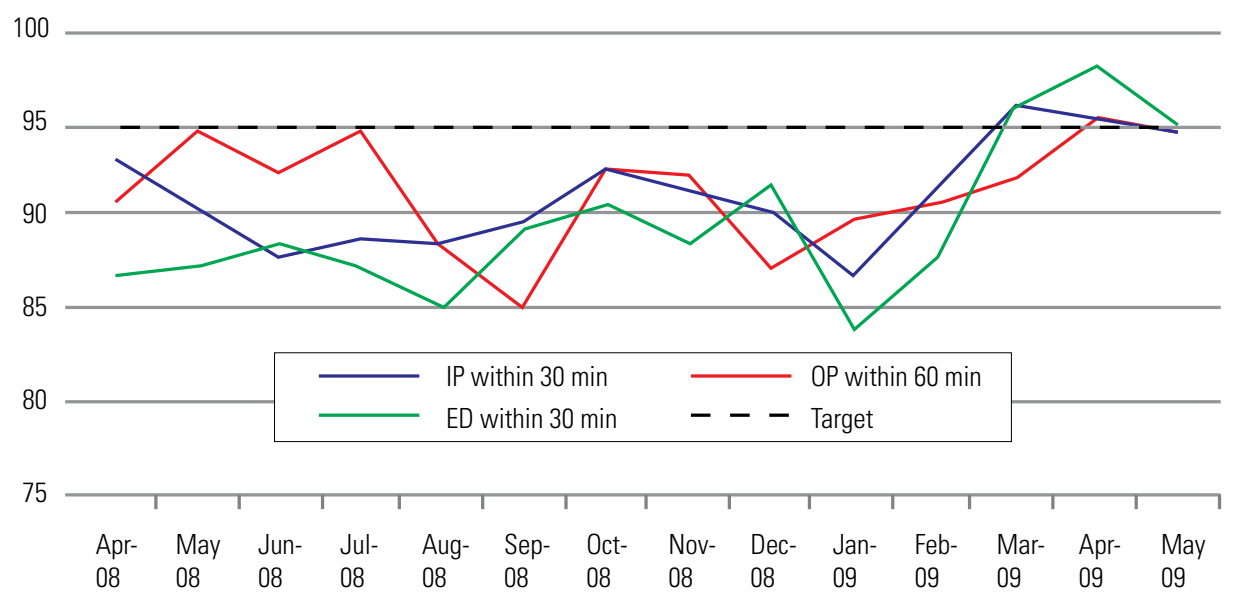

$\mathrm{CTR}=$ critical test results; $\mathrm{ED}=$ patients in the emergency department; $\mathrm{IP}=$ in-patients; $\mathrm{OP}=$ outpatients. of laboratories or individual clinical services, with limited success.

- There are merits of an inter-professional team (i.e., laboratory and clinical leaders) working together to address a mutually important issue.

- There is value in learning from failures (i.e., CTR cases where calling targets were not met).

- Higher-cost but "higherleverage" approaches can be pivotal, such as the customization of the LIS callback module and the establishment of a call centre, which provided data for ongoing monitoring and was a key to

Indicators of communication of CTR are reported on the hospital's monthly quality indicator report and reviewed by hospital leaders. Figure 2 shows that, as of November 2008, $>85 \%$ of calls were being made within the appropriate time frames established for in-patients, patients in the emergency department and outpatients.

A formal chart audit was also conducted to assess documentation compliance with staff receiving ED patient and in-patient CTR calls. A sample of 175 CTR calls involving 110 patient charts over a two-week period was studied. Sixty-nine percent of the charts showed evidence of the team's awareness of the CTR and actions undertaken with respect to patient care, with approximately $50 \%$ of these being documented by nurses and $50 \%$ by physicians or delegates. Challenges to completing documentation included priority being given to providing direct care needs for acutely unstable patients versus documentation (e.g., awaiting transfer to the critical care unit); the use of incomplete entries such as "blood work done" or "to be repeated"; unclear expectations for accepting CTR on behalf of anesthetists; and some parameters more likely to be documented (e.g., glucose, hemoglobin) given their impact on required nursing care interventions (and orders).

\section{Lessons Learned}

A number of lessons were learned as we carried out this initiative, including the following:

- There is great value in reviewing a complicated process such as the communication of CTR as a series of interdependent sub-processes. In the past, change strategies for the communication of CTR were tackled only from the perspectives sustainable long-term improvement.

- Regular (e.g., daily and monthly reporting) monitoring and vigilance are needed to make sure that practices are sustained and to ensure the early identification of issues and problems.

\section{Conclusions and Next Steps}

Improvements to SickKids' processes for the communication of critical laboratory test results required, first of all, the will to change, ideas promising change strategies and the execution of multiple aligned initiatives to produce system-level results. Our data have shown, however, that we still have work to do. The IHI framework (Nolan 2007) invites healthcare organizations and quality improvement teams not achieving the intended results to ask whether this is due to any of the following:

\section{- A lack of organizational will?}

- An absence of strong enough ideas for improvement?

- A failure to execute changes?

- Unanticipated internal or external forces?

To date, a significant investment of human energy and time has been directed toward putting in place effective structures and processes for communicating CTR; we will now turn our attention to identifying factors contributing to the $5-10 \%$ of CTR communications not meeting established targets for reliability and timeliness. As with the work to date, this additional step will involve laboratory and clinical leadership continuing their collaborative journey toward seeking stronger ideas for sustainable improvement and risking implementing change initiatives. A study of 121 institutions' timeliness of CTR communica- 


\section{It has now been more than 12 months since the occurrence of a significant CTR missed call.}

tions concluded "that the absolute interval represents one of the least important vulnerabilities in the process that leads to timely correction of a critical laboratory result. More fruitful areas for local monitoring and quality improvement include: results that are not called or calls that are abandoned; time it takes caregivers to respond to findings of critical abnormalities; and problems communicating critical results for outpatients" (Valenstein et al. 2008,p.1867). This view underscores our need to continually address "outliers" - that is, missed calls or calls to inappropriate care providers - and to understand why they persist. HQ

\section{Acknowledgements}

We give special thanks to Bonnie Reib, managing director of pediatric laboratory medicine; Sal Matteliano, team leader, of the rapid response laboratory; and all laboratory staff for their leadership and commitment to improving processes for the communication of CTR at SickKids.

\section{References}

Canadian Council on Health Services Accreditation. 2007. CCHSA Patient/Client Safety Goals and Required Organizational Practices (ROPs). Version 2.1. Ottawa, ON: Author.

Dighe, A.S., A. Rao, A. Coakley and K.B. Lewandrowskl. 2006. "Analysis of Laboratory Critical Value Reporting at a Large Academic Medical Center." American Journal of Clinical Pathology 125: 1-7.

Hanna, D., P. Griswold, L. Leape and D. Bates. 2005. "Communicating Critical Test Results: Safe Practice Recommendations." Joint Commission Journal on Quality and Patient Safety 31(2): 68-80.

Howanitz, P.J., S.J. Steindel and N.V. Heard. 2002. "Laboratory Critical Values Policies and Procedures: a College of American Pathologists Q-Probes Study in 623 Institutions." Archives of Pathology and Laboratory Medicine 126: 663-69.

Joint Commission. 2006. "2005 National Patient Safety Goals: Hospital.” Retrieved June 2, 2009. <http://www.jointcommission.org/ General Public/NPSG/05_gp_npsg.htm.>

Joint Commission. 2008. "Accreditation: 2007 Most Challenging Standards." Joint Commission OnLine September. Retrieved June 2, 2009. <http://www.jointcommission.org/Library/jconline/jconline_ sept_2008.htm.>

Langley, G.L., K.M. Nolan, T.W. Nolan, C.L. Norman and L.P. Provost. 2006. The Improvement Guide: A Practical Approach to Enhancing Organizational Performance. San Francisco, CA: Jossey-Bass.

Nolan, T.W. 2007. Execution of Strategic Improvement Initiatives to Produce System-Level Results. IHI Innovation Series White Paper. Cambridge, MA: Institute for Healthcare Improvement. Retrieved December 21, 2008. <http://www.ihi.org/IHI/Results/WhitePapers/ ExecutionofStrategicImprovementInitiatives.>

Schiff, G.D., ed. 2006. Getting Results - Reliably Communicating and Acting on Critical Test Results. Ottawa, ON: Oakbrook Terrace, Illinois: Joint Commission Resources, Inc.
Stevens, P., A. Matlow and R. Laxer. 2005. "Building from the Blueprint for Patient Safety at the Hospital for Sick Children." Healthcare Quarterly 8: 132-39.

Valenstein, P., E.A. Wagar, A. Stankovic, M.K. Walsh and F. Schneider. 2008. "Notification of Critical Results: A College of American Pathologists Q-Probes Study of 121 Institutions." Archives of Pathology and Laboratory Medicine 132: 1862-67.

Zettle, R. 2006. "The Importance of Follow-Up Systems - Diagnostic Imaging Studies, EKGs and Laboratory Results." HIROC Connection 8: 3-6.

\section{About the Authors \\ Cheryl Jackson, MHSc (N), is a quality analyst in quality and risk management at The Hospital for Sick Children, Toronto, Ontario.}

Maureen MacDonald, CQM (ASQ), is the team leader of quality systems, pediatric laboratory medicine, at The Hospital for Sick Children.

Michael Anderson, BSc, is the team leader of laboratory information systems, pediatric laboratory medicine, at The Hospital for Sick Children.

Polly Stevens, MHSc, is the director of quality and risk management at The Hospital for Sick Children and a lecturer in the Department of Health Policy, Management and Evaluation, University of Toronto, Toronto, Ontario.

Philip Gordon, MD, FRCPC, is the chief of pediatric laboratory medicine at The Hospital for Sick Children and a professor of laboratory medicine and pathobiology at the University of Toronto.

Ronald Laxer, MD, FRCPC, is the vice-president of medical and academic affairs at The Hospital for Sick Children and a professor of pediatrics and medicine, University of Toronto. 